\title{
The Prognostic Significance of Elevated Cardiac Troponin in Non- Cardiac Medical Disorders. Pilot Study
}

\author{
Ibrahim AlQassas, MD, Walid Hassan, MD, MACP*, Nadia Sunni, MD, Mohammed \\ Lhmdi, MD, Alaa Nazzal, MD, Mohammed J Mohamed, Farhan Dar, MD, Sahar \\ Sharafeldin, MD, Amr Aljareh, MD, Hasan Balubaid, MD, Basema Alshengiti, MD, \\ Ehab Hasan, MD, Heba Waez, MD, Sarah Bahnshal, MD, Momen Nassani, MD, \\ Mohammed Al-Kulak, MD, Maha AIKudsi, MD, Hala Zein Elabidinm, MD, Khaldoun \\ Alsaadi, MD, and Ibrahim Mansour, MD
}

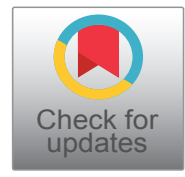

Department of Cardiovascular Disease, International Medical Center, Jeddah, Saudi Arabia

*Corresponding author: Walid Hassan, MD, MACP, FAHA, FACC, FACCP, FSCAI Professor of Medicine, Director of the Cardiac Center of Excellence, International Medical Center, P.O. Box 2172, Jeddah 21451, Saudi Arabia, Tel: +966-12-6509000, Fax: +966-12-650-9789, E-mail: whassan@imc.med.sa, walidhassan275@gmail.com

\begin{abstract}
Background: Several studies have linked elevated cardiac troponin to increased overall risk in patients with acute coronary syndrome but the prognostic significance of elevated troponin in non-cardiac conditions remains scanty.

Objectives: The primary aim of this study was to investigate the prognostic significance of elevated high sensitivity troponin $\mathrm{T}$ (TnT-HS) in non-cardiac disorders outside the remit of an acute coronary syndrome (ACS). Secondarily we aimed to investigate the impact of cardiovascular comorbidities and other clinical presentations in the release of cardiac biomarkers in non-cardiac disorders.
\end{abstract}

Methodology: This was a retrospective electronic patient record pilot review where all patients with elevated TnT-HS without acute coronary syndrome, recent angioplasty or heart failure within a three month period were enrolled into the study and subsequently followed prospectively for a six month period. From January 1, 2016 to June 30, 2016, a total of 2535 patients were screened of which 306 patients had elevated TnT-HS and 162 patients met the study inclusion criteria.

Data were encrypted and collected in Google database format, exported into excel spreadsheet, analyzed and computed using SPSS (version 24) to identify clinical associations with increased values of TnT-HS.

Results: Most troponin TnT-HS samples (77.1\%) were obtained from emergency room (ER) attendance and $63.4 \%$ of patients were male. The mean age was 72 years and no correlation were found between age and troponin levels (rs $=-0.18, p=0.816$ ) by Spearman Rank-order correlation. Although expectedly patients with diagnosis of acute coronary syndrome displayed TnT-HS values significantly higher than those of other groups, positivity to TnT-HS (> $40 \mathrm{ng} / \mathrm{l}$ ) was also observed in patients with other clinical conditions. In multivariate analysis, baseline chronic kidney disease (CKD), acute infectious diseases mainly urinary tract infection and cerebrovascular events (CVA) were independently associated with TnT-HS positivity at admission. Observations from the cohort as a whole; TnT-HS positivity exhibited high sensitivity and negative predictive value, counterbalanced by low specificity and limited positive predictive value. Major adverse cardiac and cerebral events (MACCE) were significant within 6 months including; Death $(13.7 \%)$, MI (3.9\%), Stroke (ischemic $4.6 \%$, hemorrhagic $2.3 \%$, TIA $0.8 \%$ ) - $\mathrm{p}$ value $<0.02$.

Conclusions: TnT-HS positivity should be cautiously interpreted in patients exhibiting non acute cardiac conditions associated CKD, infections, and CVAs. This troponin elevation in non-cardiac conditions still carries a significant adverse prognosis.

After adjusting for age and renal insufficiency, we can suggest a new cut off level of TnT-HS > $30 \mathrm{ng} / \mathrm{l}$ to have increased risk of MACCE within 180 days in non-cardiac conditions.

\section{Keywords}

Troponin T high sensitivity, Non-cardiac disease, Significance, Outcomes

Citation: AlQassas I, Hassan W, Sunni N, Lhmdi M, Nazzal A, et al. (2019) The Prognostic Significance of Elevated Cardiac Troponin in Non-Cardiac Medical Disorders. Pilot Study. Int J Clin Cardiol 6:136. doi.org/10.23937/2378-2951/1410136

Accepted: February 12, 2019; Published: February 14, 2019

Copyright: (C) 2019 AlQassas I, et al. This is an open-access article distributed under the terms of the Creative Commons Attribution License, which permits unrestricted use, distribution, and reproduction in any medium, provided the original author and source are credited. 


\section{Introduction}

Troponins are proteins that facilitate contraction of cardiac muscle by binding with actin and tropomyosin. Each troponin ( $\mathrm{Tn})$ complex is composed of three subunits - TnC, TnT and Tnl. TnC binds calcium and regulates activation during contraction. $\mathrm{TnT}$ binds the complex to tropomyosin while $\mathrm{Tnl}$ inhibits binding in the absence of activation [1-5].

Troponins are expressed in cardiac and skeletal muscles (fast and slow). TnC is found as a single isoform in all three sources. TnT and Tnl on the other hand, exist as different isoforms in each type of muscle cell. This has led to the development of specific assays for the cardiac isoforms of Troponin T, I, and Troponin T high sensitivity (CTnT, CTnl, and TnT-HS) to indicate myocardial injury [2-5].

Cardiac troponin I CTnl is only produced in myocytes, while CTnT is found in small amounts in skeletal muscles. The, most specific assays for myocardial injury measure for CTnl $[5,6]$.

Cardiac troponins were introduced in the year 2000 by the American and European guidelines to diagnose acute coronary syndromes caused by thromboembolic disease [6]. Their use has expanded to indicate myocardial injury caused by obstructive and nonobstructive coronary artery disease and they were found to carry prognostic significance [6-19].

Elevation of cardiac troponins has been noted to occur in heart failure, renal failure, pulmonary embolism, respiratory failure, stroke, anemia, and other medical disorders.

The pathophysiology is thought to be related to myocardial injury caused by noxious stimuli, stretch and hypoxia [7-28].

This has led to the classification of type 1 versus type 2 myocardial infarction (MI) [29,30]. Type 1 myocardial infarction denotes myocardial injury caused by hypoperfusion to myocytes because of atherosclerotic/thromboembolic disease. It includes the spectrum of acute coronary syndromes: Unstable angina and myocardial infarction with or without ST changes. Patients present with characteristic chest pain and elevated cardiac troponins and will require urgent reperfusion therapy to salvage the myocardium (2013 ACCF/AHA guidelines for STEMI and the 2014 AHA/ACC guidelines for NSTEMI).

Type 2 myocardial infarction is thought to be caused by supply-demand mismatch to the myocytes because of systemic hypoperfusion or noxious stimuli. Therapy is directed at treating the underlying cause. It has been reported that patients with type $2 \mathrm{MI}$ and elevated cTnl had increased risk of death within 6 months compared to those without MI [29-30].
In this study, our primary aim was to investigate further the prognostic significance of elevated TnT-HS in non-cardiac disorders. The secondary aim of this study was to investigate the effect of cardiovascular comorbidities in raising cardiac biomarkers in noncardiac disorders.

\section{Methodology}

\section{Study design}

This is a retrospective electronic pilot cohort review over 6 months conducted in International Medical Center (IMC)- Jeddah from January 2016 to June 2016.

\section{Objectives}

1. To evaluate the prognostic significance of elevated TnT-HS in different non-cardiac medical disorders indicated by the development of MACCE including myocardial infarction (MI), transient ischemic attack, stroke, or death.

2. To study cardiovascular co-morbidities effect on elevation of TnT-HS in different non-cardiac medical disorders.

\section{Operations and definitions}

A MACCE was defined as the development of MI, Stroke/TIA or death within the six month follow-up period. The 2013 ACCF/AHA guidelines for STEMI and the 2014 AHA/ACC guidelines for NSTEMI are used to define MI. Stroke and TIA are defined by the American Heart Association (AHA) guidelines published in 2013.

A master database was produced containing patients with different medical disorders who had elevated TnTHS.

\section{Data collection}

2535 patients who presented to IMC were investigated for elevated TnT-HS in the period between January $1^{\text {st }}$ to June $30^{\text {th }} 2016$ were pooled into a common database. From these patients, 162 patients met the study inclusion criteria and 31 were lost to follow-up.

\section{Inclusion criteria}

1. Elevation of cardiac troponin (CTn) above $0.050 \mathrm{ug} / \mathrm{L}$ TnT-HS > $30 \mathrm{ng} / \mathrm{l}$

2. Patients admitted with non-cardiac medical diagnoses.

\section{Exclusion criteria}

1. Acute coronary syndrome or MI during the index admission.

2. Coronary intervention within the past one month.

3. Patients with a myocardial infarction within the past one month.

A web-based questionnaire was developed and a 
team of data collectors gathered the following data:

1. Demographic data (age, gender, weight, height, BMI)

2. Location where sample was collected

3. CK, CKMB, CTn, TnT-HS Levels, LDH (in case of serial tests, the highest value will be considered as the index value).

4. D Dimmer, BNP

5. Complete blood counts

6. Creatinine, Glomerular Filtration Rate, Blood Urea Nitrogen, Sodium, Potassium

7. ALT

8. Calcium, Magnesium, Albumin

9. TSH, HBA1C

10. CRP

11. Echocardiographic Findings (baseline at the initial episode and over the six-month follow-up period).

12. ECG findings

13. Final Diagnosis

14. Presence of CVS co-morbidities (Diabetes, Hypertension, Dyslipidemia, Smoking, Obesity).

15. Diagnosis of MACCE after the sample was drawn over the six-month follow-up period.

Estimation of serum Troponin T (TnT) was done using highly sensitive electrochemiluminescence immunoassay based on sandwhich assay principle. The measuring range of assay is 3-10000 $\mathrm{ng} / \mathrm{L}$. The patient testing was performed after calibration and control were satisfied as per manufacturer standard recommendations for TnT.

\section{Data analysis}

All data were collected using a web-based questionnaire, exported into an Excel ${ }^{\circledR}$ spreadsheet and computed using SPSS version 24. Qualitative Data:

1. Frequencies and percentages are used to find out the incidence of elevated CB-TnT-HS in different non-cardiac medical disorders.

2. Chi Square was used to assess significance of categorical variables, $p$ value $<0.05$ was considered significant.

3. All decimal places were rounded to 2 significant figures.

\section{Quantitative data}

1. Means and standard deviations of elevated $C B$ in different non-cardiac medical themes were produced.

2. We tested the variable troponin by using ShapiroWilk test for normal distribution. We used two nonparametric tests: Kruskal-Wallis and Man-Whitney test to compare mean troponins between different themes and between patients who developed and did not develop major CVS events respectively.

3. We examined a new cut-off value (threshold) of biomarker elevation that may be a surrogate level by constructing area-under the curve graphs to facilitate prognostic significance in non-cardiac medical disorders.

4. Chi square and multi-nominal logistic regressions were used to study CVS co-morbidities effect on elevation of CB TnT-HS in different non-cardiac medical disorders.

\section{Ethical considerations}

Approval for the study was obtained from the hospital Research and Ethics Committee. Consent for the study was deemed unnecessary because it was a retrospective electronic records review with no patient identification or interaction. A customized encrypted coding scheme was incorporated to ensure patient confidentiality.

Table 1: Presenting the location where Troponin samples were obtained and Gender.

\begin{tabular}{|l|l|l|}
\hline Location & Frequency (Percentage) & P value \\
\hline ICU & $12(9.2)$ & 0.168 \\
\hline ER & $101(77.1)$ & 0.49 \\
\hline CCU & $2(1.5)$ & 0.415 \\
\hline Medical Floor & $15(11.5)$ & 0.623 \\
\hline Surgical Floor & $1(0.8)$ & 0.56 \\
\hline \multicolumn{2}{|l|}{} \\
\hline Gender & Frequency (Percentage) & \\
\hline Male & $83(63.4)$ & 0.969 \\
\hline Female & $48(36.6)$ & \\
\hline
\end{tabular}

Table 2: Summarizing the different themes and diagnoses. Themes were compared using chi-square, significance was chosen at 0.05 .

\begin{tabular}{|l|l|l|l|l|}
\hline Theme & Diagnosis & Total & Percentage & P value \\
\hline Infectious & Urinary Tract Infection [22], Pneumonia [15], other infections [15] & 52 & 39.69 & 0.262 \\
\hline Other & Patient admitted with non-specific final diagnosis. & 33 & 25.19 & 0.125 \\
\hline Renal & AKI upon CKD [11], Renal Failure on dialysis [11] & 22 & 16.79 & 0.77 \\
\hline Neurological & $\begin{array}{l}\text { Ischemic Stroke [6], Hemorrhagic Stroke [3], other neurological } \\
\text { diagnoses [5] }\end{array}$ & 14 & 10.69 & $<0.05$ \\
\hline Respiratory & $\begin{array}{l}\text { Pulmonary Embolism [4], Respiratory Failure [2], other respiratory } \\
\text { diagnoses [4]. }\end{array}$ & 10 & 7.63 & 0.262 \\
\hline Total & & 131 & 100 & \\
\hline
\end{tabular}




\section{Results}

In the interval between January to July 2016, 162 patients met the inclusion criteria of the study, from this group 31 were lost to follow-up. Most troponin TnT-HS samples (77.1\%) were obtained from the ER and $63.4 \%$ of patients were male ( $p$ value $>0.05$ ) (Table 1 ).

The mean age of the sample was 72 years. No correlation was found between age and troponin levels by Pearson.

Medical disorders were grouped into 5 different themes; infectious, renal, neurological (CNS), respiratory and others. The most prevalent theme was infectious (39.7\%) and the most prevalent diagnosis was urinary tract infection (Table 2). Patients with gastroenterology, rheumatology, haematology and

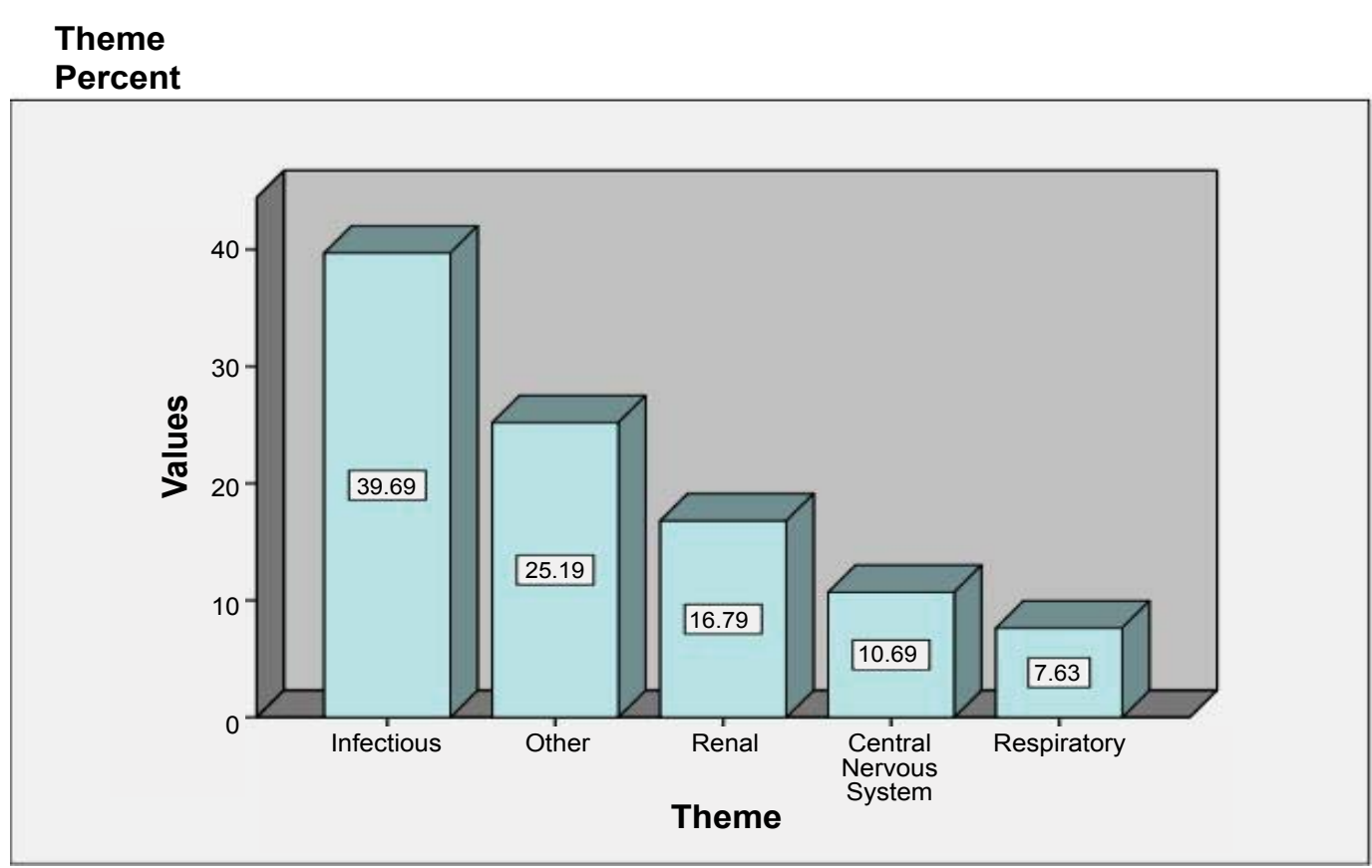

Figure 1: Summarizing the prevalence of different themes.

Table 3: Summarizing the difference between themes using chi-square. $P$ value $<0.05$ was considered significant.

\begin{tabular}{|l|l|l|l|}
\hline Parameter (Number of Patients) & Yes (Percentage) & No (Percentage) & p value \\
\hline Major CVS event (131) & $33(25.2)$ & $98(74.8)$ & 0.040 \\
\hline New DDx (59) & $21(35.6)$ & $38(64.4)$ & 0.941 \\
\hline RWMA (87) & $28(32.2)$ & $59(67.8)$ & 0.832 \\
\hline Decrease in EF (80) & $12(15)$ & $68(85)$ & 0.88 \\
\hline
\end{tabular}

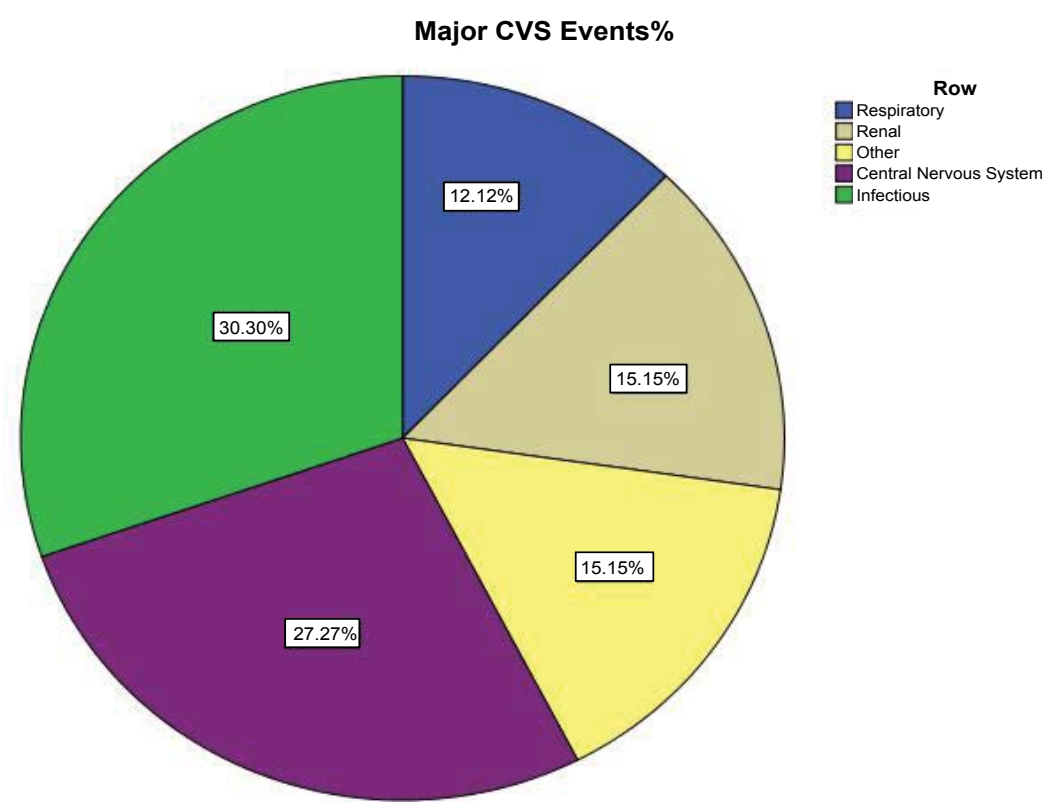

Figure 2: Summarizing the percentages of different themes in patients who developed Major CVS events. 
where no specific diagnosis was reached were classified as -Other given their small proportion of the sample. The third most prevalent theme was renal, followed by CNS and respiratory (Figure 1). There was no significant difference in echo and ECG findings between different themes by chi square ( $p$ value $>0.05$ ) (Table 3 ).

Of the patients who actually developed a major CVS event, $30.3 \%$ initially had an infectious etiology
Table 4: Comparing different themes with developing Major CVS event. Chi-square was used, $p$ value $<0.05$ was considered significant.

\begin{tabular}{|l|l|l|l|}
\hline Major CVS Event & \multicolumn{3}{l|}{} \\
\hline Theme & No & Yes & P value \\
\hline CNS & 5 & 9 & $<0.05$ \\
\hline Infectious & 42 & 10 & 0.202 \\
\hline Respiratory & 6 & 4 & 0.262 \\
\hline Renal & 17 & 5 & 0.77 \\
\hline Other & 28 & 5 & 0.125 \\
\hline
\end{tabular}
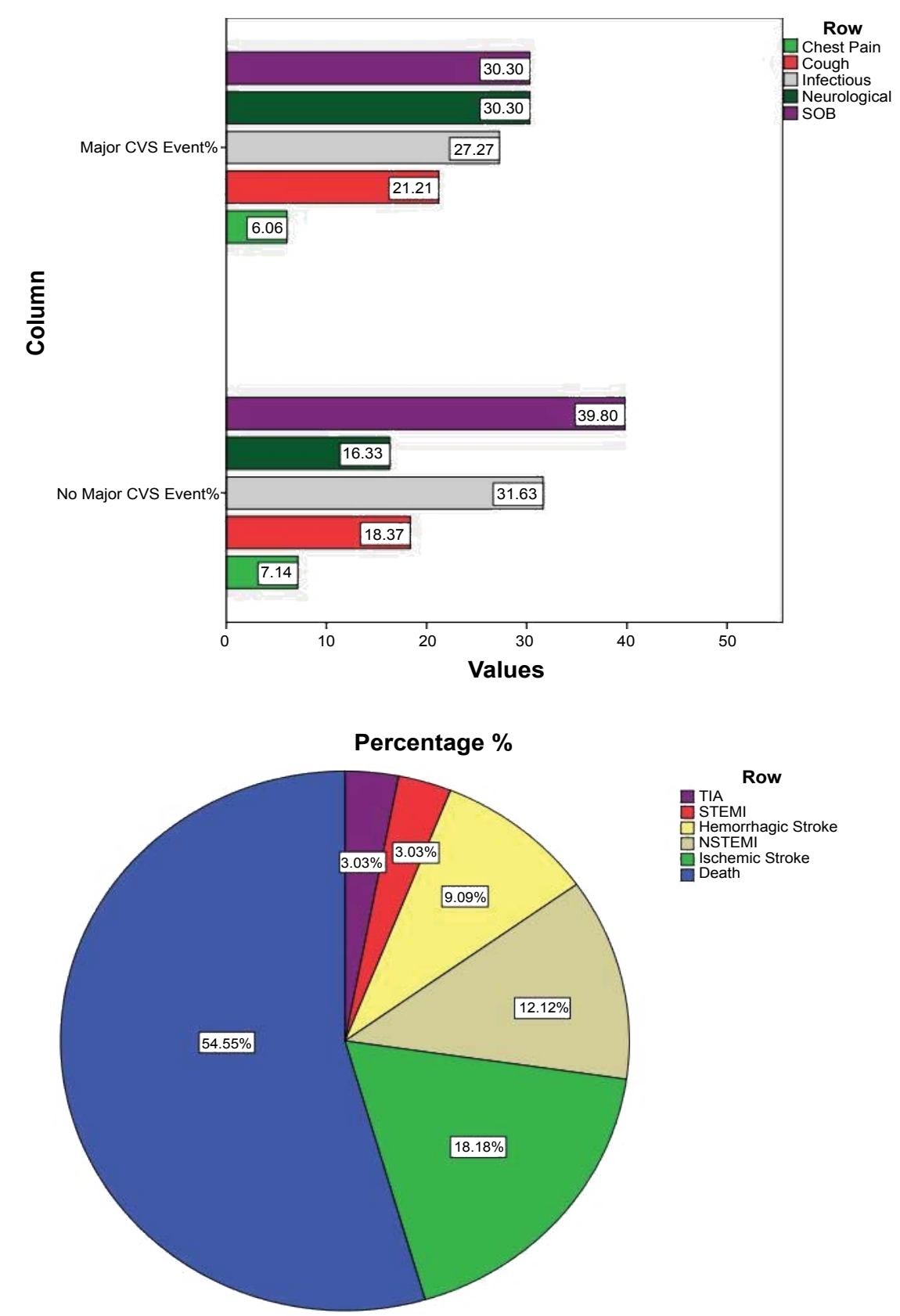

\begin{tabular}{|l|l|l|}
\hline & Frequency & Percentage \\
\hline Type Death & 18 & $54.55 \%$ \\
\hline Ischemic Stroke & 6 & $18.18 \%$ \\
\hline NSTEMI & 4 & $12.12 \%$ \\
\hline TIA & 1 & $3.03 \%$ \\
\hline Hemorrhagic Stroke & 3 & $9.09 \%$ \\
\hline STEMI & 1 & $3.03 \%$ \\
\hline Total & 33 & $100.00 \%$ \\
\hline
\end{tabular}

Figure 3: a) Summarizing the initial chief complaints in patients who developed and did not develop Major CVS events; b) Summarizes the different types of Major CVS events. 
and $27 \%$ a CNS etiology (Figure 2). We used chi-square to compare the risk of developing a major CVS event between different themes. The only theme that was significant was the neurological $(p<0.05)($ Table 4$)$.

The most common symptom observed in patients who developed major CVS events was short-

Table 5: Summarizing the initial chief complaints in patients who developed and did not develop Major CVS events.

\section{MACCE}

\begin{tabular}{|l|l|l|l|}
\hline & No & Yes & P value \\
\hline Chest Pain & 7 & 2 & 0.832 \\
\hline SOB & 39 & 10 & 0.33 \\
\hline Cough & 18 & 7 & 0.719 \\
\hline "Infectious & 31 & 9 & 0.638 \\
\hline "Neurological & 16 & 10 & 0.082 \\
\hline
\end{tabular}

*(mainly decrease in LOC) ${ }^{* *}$ (mainly fever). ness of breath and neurological symptoms such as decrease level of consciousness (LOC) $(30.30 \%$ each) followed by infectious symptoms such as fever $(27 \%)$ and cough $(21 \%)$. Chest pain was the least observed symptom (6\%) (Figure 3 and Table 5). There was no significant difference between symptoms and developing major CVS events ( $p>0.05$ ). Table 6 illustrates the different major CVS event and their time-course. Most major CVS events were deaths (13.7\%) followed by Ischemic stroke (4.6\%) (Figure 3).

The mean troponin of the data sample was 0.27 (27 $\mathrm{ng} / \mathrm{l}) \pm(\mathrm{SD}) 0.54(54 \mathrm{ng} / \mathrm{l})$. We tested the variable troponin by using Shapiro-Wilk test and found that it was not normally distributed ( $p$ value $<0.05$ ). We used two non-parametric tests: Kruskal-Wallis and Man-Whitney Test to compare mean troponins between different

Table 6: Summarizing the different Major CVS events and their time course.

\begin{tabular}{|c|c|c|c|c|c|c|c|c|}
\hline Time & Death & STEMI & NSTEMI & $\begin{array}{l}\text { Ischemic } \\
\text { Stroke }\end{array}$ & TIA & HMG Stroke & No Event & Total \\
\hline $\begin{array}{l}\text { During index } \\
\text { hospitalization }\end{array}$ & 8 & 0 & 0 & 4 & 1 & 2 & 0 & 15 \\
\hline$<30$ days & 2 & 1 & 1 & 0 & 0 & 1 & 0 & 5 \\
\hline 1-3 months & 2 & 0 & 1 & 1 & 0 & 0 & 0 & 4 \\
\hline 3-6 months & 6 & 0 & 2 & 1 & 0 & 0 & 0 & 9 \\
\hline No event & 0 & 0 & 0 & 0 & 0 & 0 & 98 & 98 \\
\hline Total (Percentage) & $18(13.7)$ & $1(0.8)$ & $4(3.1)$ & $6(4.6)$ & $1(0.8)$ & $3(2.3)$ & $98(74.8)$ & 131 \\
\hline
\end{tabular}

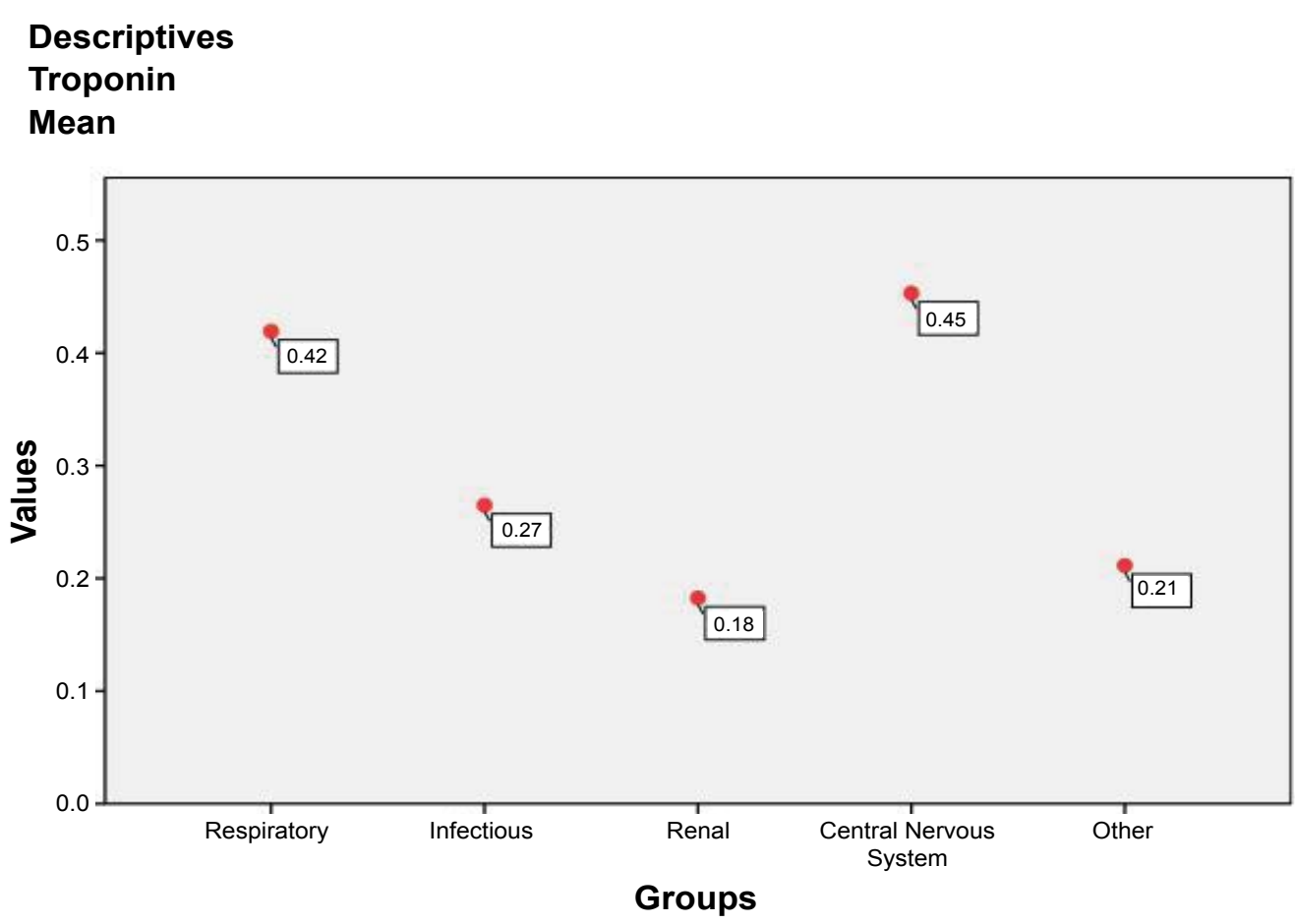

\begin{tabular}{|l|r|r|r|r|}
\hline & Frequency & Mean Troponin TnT-HS ng/l & Std. Deviation ng/l \\
\hline Respiratory & 10 & 42 & 97 \\
\hline Infectious & 52 & 27 & 48 \\
\hline Renal & 22 & 18 & 13 \\
\hline Central Nervous System & 14 & 45 & 2 \\
\hline Other & 33 & 21 & 31 \\
\hline Total & 131 & 27 & 54 \\
\hline
\end{tabular}

Figure 4: Comparing means of troponins encountered in different themes. 


\section{Descriptives Troponin Mean}
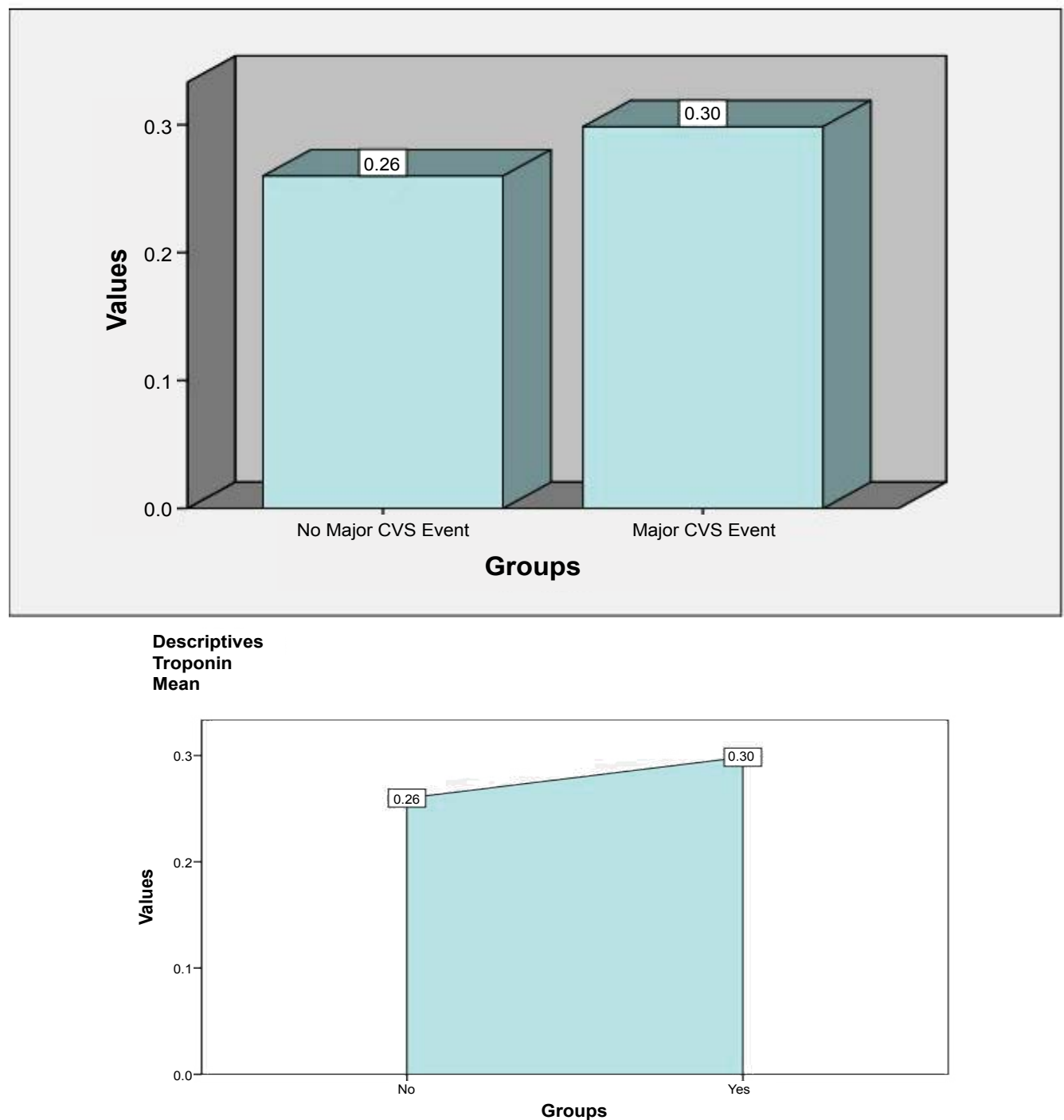

\begin{tabular}{|l|l|l|l|}
\hline & N & Mean Troponin & Std. Deviation \\
\hline No Major CVS Event & 98 & 0.26 & 0.54 \\
\hline Major CVS Event & 33 & 0.3 & 0.55 \\
\hline Total & 131 & 0.27 & 0.54 \\
\hline
\end{tabular}

Figure 5: Comparing means of troponins between patients who developed and did not develop major CVS events.

themes and between patients who developed and did not develop major CVS events respectively. The highest means of troponin were observed in patients with CNS diagnoses $0.45(45 \mathrm{ng} / \mathrm{l}) \pm$ SD 1.02 (102 ng/l) followed by Respiratory (0.42 (42 ng/l) \pm SD $0.97(97 \mathrm{ng} / \mathrm{l})$, however the difference between themes was not significant ( $p$ $>0.05$ ) (Figure 4). Patients who developed CVS events had a higher troponin mean 0.30 (30 ng/l) \pm SD 0.55 (55 $\mathrm{ng} / \mathrm{l})$ compared to patients who did not $(0.26(26 \mathrm{ng} / \mathrm{l}) \pm$ SD 0.54 (54 ng/l), however the difference was not statistically significant as assessed ( $p>0.05$ ) (Figure 5).

The most prevalent comorbidities observed in the data sample are presented in Figure 6. In the Major CVS patient group, hypertension (HTN) was most prevalent followed by diabetes (DM) and chronic kidney disease
(CKD). We used chi-square to compare the difference in comorbidities between the group of patients who developed Major CVS events and those who did not; only CKD was observed to be significantly different ( $p$ value $<0.05$ ). However, when we performed nominal logistic regression on the data sample, the difference between comorbidities in both groups including CKD was not significant $(p>0.05)$ (Table 7).

\section{Discussion}

Elevated cardiac troponins occur at times of myocardial injury [6-28]. The etiology was initially thought to be due to ischemia secondary to the ACS paradigm involving obstruction of the coronary arteries [9-31]. Cardiac troponin elevation can occur in other diseases and does not necessarily indicate the presence of a thrombotic 


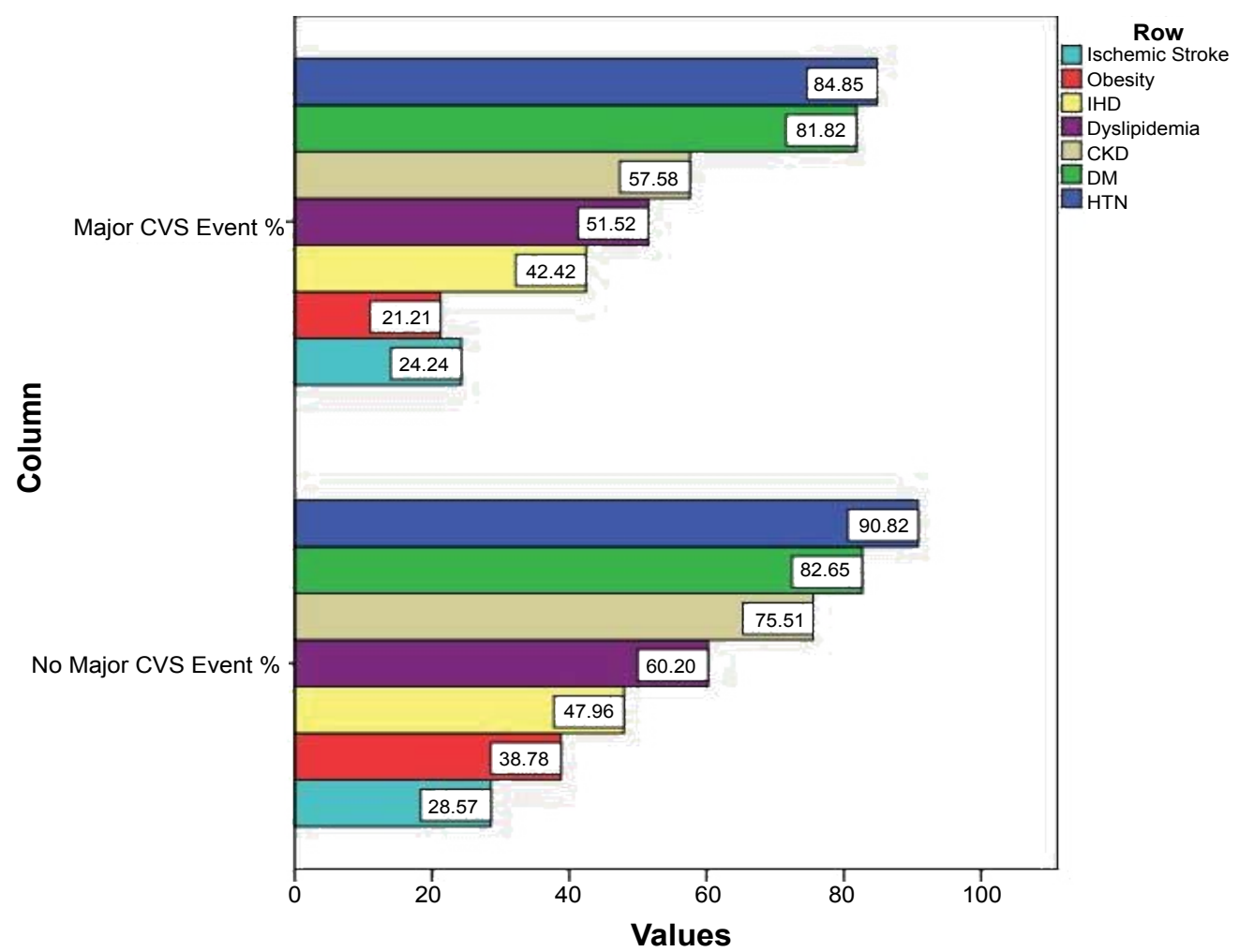

Comorbidity Table (simple chi-square)

\begin{tabular}{|l|l|l|l|}
\hline & No Major CVS Event & Major CVS Event & P Value \\
\hline DM & 81 & 27 & 0.913 \\
\hline HTN & 89 & 28 & 0.337 \\
\hline Dyslipidemia & 59 & 17 & 0.382 \\
\hline IHD & 47 & 14 & 0.581 \\
\hline Stroke HMG & 3 & 0 & 0.309 \\
\hline Stroke ISchemic & 28 & 8 & 0.63 \\
\hline TIA & 3 & 0 & 0.309 \\
\hline CKD & 74 & 19 & $0.050^{*}$ \\
\hline Obesity & 38 & 7 & 0.066 \\
\hline Smoking & 9 & 2 & 0.576 \\
\hline Asthma & 4 & 3 & 0.268 \\
\hline COPD & 10 & 1 & 0.199 \\
\hline AFlb & 9 & 5 & 0.337 \\
\hline OSA & 6 & 1 & 0.495 \\
\hline Hypothyroidism & 16 & 5 & 0.874 \\
\hline HF & 11 & 1 & 0.158 \\
\hline
\end{tabular}

Figure 6: Illustrating the comorbidities in the studied population.

Table 7: Summarizing the different lab results in the studied population.

\begin{tabular}{|l|l|l|l|l|l|}
\hline & N & Minimum & Maximum & Mean & Std. Deviation \\
\hline Age (years) & 131 & 22 & 99 & 71.87 & 12.14 \\
\hline CKMB ug/L & 130 & 0.7 & 161 & 7.76 & 19.66 \\
\hline CK U/L & 130 & 1.8 & 1466 & 171.23 & 234.82 \\
\hline BNP $(\mathrm{pg} / \mathrm{mL})$ & 56 & 52 & 174569 & 16229.23 & 26083.05 \\
\hline D dimer $(\mathrm{mg} / \mathrm{L})$ & 12 & 0.17 & 61 & 11.24 & 18.64 \\
\hline Lactate $(\mathrm{mmol} / \mathrm{L})$ & 67 & 0.32 & 24 & 2.39 & 3.03 \\
\hline Hgb (d/dL) & 131 & 5.4 & 18.7 & 11.14 & 2.39 \\
\hline WBC $(10 \times 9 / \mathrm{L})$ & 131 & 3.52 & 38 & 10.98 & 5.5 \\
\hline Platelets (10 $\times$ 9/L) & 131 & 38 & 555 & 239.12 & 85.99 \\
\hline Creatinine (umol/L) & 131 & 27 & 1700 & 298.34 & 282.65 \\
\hline GFR Cystatin & 113 & 2.6 & 114.5 & 27.26 & 26.33 \\
\hline GFR Creatinine & 54 & 3 & 223 & 39.09 & 41.77 \\
\hline Na (mmol/L) & 131 & 115 & 168 & 136.83 & 6.2 \\
\hline
\end{tabular}




\begin{tabular}{|l|l|l|l|l|l|}
\hline $\mathrm{K}(\mathrm{mmol} / \mathrm{L})$ & 131 & 2.3 & 8.1 & 4.51 & 0.84 \\
\hline BUN (mmol/L) & 131 & 0.82 & 62.3 & 17.9 & 13 \\
\hline ALT (U/L) & 88 & 3 & 377 & 25.23 & 43.04 \\
\hline Albumin (g/L) & 99 & 12 & 48 & 34.59 & 5.8 \\
\hline LDH (mg/dL) & 91 & 82 & 1337 & 241.84 & 143.19 \\
\hline Ca (mmol/L) & 88 & 1.55 & 226 & 4.68 & 23.87 \\
\hline Mg (mmol/L) & 89 & 0.44 & 2.53 & 0.83 & 0.26 \\
\hline CRP (mg/L) & 97 & 0.62 & 513.48 & 82.62 & 100.36 \\
\hline TSH (m/U/L) & 89 & 0.28 & 14.36 & 2.92 & 2.6 \\
\hline HBA1C (\%) & 86 & 4.3 & 12.5 & 7.52 & 1.95 \\
\hline Small LDL (mmol/L) & 37 & 0.1 & 1.86 & 0.64 & 0.39 \\
\hline Cholesterol (mmol/L) & 43 & 1.6 & 6.8 & 3.76 & 1.3 \\
\hline TGY (mmol/L) & 44 & 0.3 & 3.4 & 1.31 & 0.72 \\
\hline LDL (mmol/L) & 44 & 0.7 & 4.81 & 2.2 & 1.04 \\
\hline HDL (mmol/L) & 44 & 0.5 & 2.15 & 1.08 & 0.4 \\
\hline
\end{tabular}

acute coronary syndrome as recent research has shed light on many other medical causes of troponin rise besides the ACS [29-41]. Troponin elevation was also reported in healthy young adults and children [33].

Among the 131 patients included in this study, the most common etiology associated with elevated Cardiac troponin was the infectious group, with UTI being the most common diagnosis. Sepsis is the leading cause of death in the non-cardiologic ICU. Poorly distributed nutritive blood flow and altered convective and diffusive oxygen transport during sepsis can lead to organ dysfunction and multiple organ failure. One of the causes of myocardial dysfunction is thought to be myocardial ischemia in sepsis; however, conventional biochemical parameters to detect myocardial ischemia lack sensitivity and specificity. Serum cardiac troponin T (S-TnT) was reported to have higher sensitivity and specificity in diagnosing minor myocardial injury [36-43].

This may be due to increased myocardial demand due to hypoxia, fever and hypotension which accompany sepsis conditions [42]. Spies and colleagues studied the elevation of cardiac troponins on 26 ICU patients with underlying sepsis and concluded 23 that elevated troponins carried a prognostic significance and were associated with higher mortality [43].

The second common medical etiology in our study was due to renal disease including end-stage renal disease on hemodialysis and acute on chronic kidney disease. Cardiovascular disease is a major cause of morbidity and mortality among patients with chronic kidney disease and those on hemodialysis accounting for approximately $50 \%$ of deaths [42-44]. Measuring troponins among this group of patients is often misleading as they tend to have higher troponin levels than other sub-groups due to reduced renal clearance [45]. In patients with renal disease, elevated troponins have a low sensitivity to diagnose acute coronary syndrome (high false positive), and thus should be used with caution when assessing prognosis [46].

Respiratory disorders causing elevated troponins included respiratory failure, obstructive airway disease and pulmonary embolism. The hypoxia associated with respiratory disorders causes' myocardial injury leading to type 2 MI $[29,30]$. In recent studies, elevation of troponin I in patients with chronic obstructive pulmonary disease was an independent predictor of the need for non-invasive mechanical ventilation [47-49]. In patients with pulmonary embolism, elevated troponins indicate a sub-massive or massive clot and are used as a risk determinant thrombolysis or embolectomy [50-56]. In one study [51] cardiac troponin levels were increased in 24 of 147 patients $(16 \%)$ with documented acute pulmonary embolism and in 20 of 594 patients (3\%) without pulmonary embolism $(p<0.001)$. In the same study patients with acute pulmonary embolisms, 8 of 24 (33\%) with increased cardiac troponin I levels and 9 of 123 (7\%) with normal cardiac troponin I levels died during hospitalization $(p<0.001)$.

Neurological diseases were important causes of troponin elevation in our study, and the only theme in which elevation of TNT-HS was associated with development of a major CVS event $(p<0.05)$. Studies have shown that aneurismal subarachnoid hemorrhage survivors and in whom the aneurysm has been occluded, had an overall increased long-term mortality rate and an increased incidence of cardiovascular events compared with age-and sex matched groups [56-61].

There is evidence that troponin may be released from the injured myocardium in response to noxious agents and hypoxia incited by different medical disorders and may reflect overall severity of illness, once coronary artery disease has been excluded [54-64]. In our study, 33 patients developed major cardiovascular events, 18 deaths, 5 ischemic strokes, 4 NSTEMI, 1 TIA, 3 hemorrhagic strokes, 1 STEMI. This MACCE denotes that elevated troponin in non-cardiac conditions confers a significant implication at 6 months clinical outcomes and is not to be ignored. Our findings are in agreement with the result of a recent cross-sectional study of high-sensitivity cardiac troponins T which concluded that Significant illnesses apart from the acute coronary syndrome 
are important causes of a rise in cTn to above the 99th percentile, and appear to reflect the total body burden of disease. Even when the high hs-cTn concentration is not due to the acute coronary syndrome, there is a significant association with all-cause mortality [57].

After adjusting for age and renal insufficiency, we can suggest a new cut off level of TnT-HS > $30 \mathrm{ng} / \mathrm{l}$ to have increased risk of MACCE within 180 days in non-cardiac conditions (Figure 5). So, in brief, cardiac troponins are released into the circulation when cardiac myocytes are damaged by acute ischemia or any other mechanism. Cardiac troponins are important for the diagnosis, risk assessment, prognosis, and determination of antithrombotic and revascularization strategies. However, troponin elevation indicates the presence, not the mechanism, of myocardial injury.

The major limitation of our study was its retrospective nature, meaning that some data could have been missed due to missing documentation. Additionally, our small cohort size, which may not be representative of the whole population and relatively short follow-up duration. Some subjects with raised troponin, we suspect had at least some form of stable pre-existing asymptomatic background coronary artery disease.

\section{Conclusions}

Our data suggest that in a mixed population, many persons will have increased troponin concentrations, without overt cardiac disease being present or manifest. While troponin is cardiac-specific, it is not ACS-specific, and any significant illness may cause a rise in troponin due to severe stress caused by the acute non-cardiac clinical event may result in a minor leakage of myocardial markers. This troponin elevation in non-cardiac conditions still carries a significant outcome on prognosis. Elevated cardiac troponin levels can be present among several non-cardiac situations including; infection, sepsis, kidney, pulmonary, neurological, and critically ill patients without evidence of myocardial ischemia. The stroke and mortality rates of troponin-positive patients are significantly higher compared with troponin-negative patients. Even minor elevations are specific for myocardial injury. We can suggest a new cut off level of $\mathrm{TnT}-\mathrm{HS}>30 \mathrm{ng} / \mathrm{l}$ to have increased risk of MACCE within 180 days in non-cardiac conditions. However, every elevated troponin level in the non-cardiac patient should not be rigorously scrutinized or treated as a myocardial infarction.

We recommend further prospective, preferably multicenter large population studies to clarify the implications various medical disorders have on cardiac biomarkers, cardiovascular events and mortality.

This research did not receive any specific grant from funding agencies in the public, commercial or not-forprofit sectors.

\section{References}

1. Vidali M, Verzotti E, Cabraz N, Santi F, Puma A, et al. (2015) Real life use of troponin in the emergency department: A survey of over 3000 cases. Biochem Med (Zagreb) 25: 421429.

2. Foy AJ, Filippone $L$ (2015) Chest pain evaluation in the emergency department. Med Clin N Am 99: 835-847.

3. Kmietowicz Z (2015) Level of troponin needed to rule out $\mathrm{MI}$ in patients with chest pain is identified. BMJ 351: 5389.

4. Maag R, Sun S, Hannon M, Davies R, Alagona P, et al. (2015) Positive predictive value of an elevated cardiac troponin for type i myocardial infarction in ED patients based on the chief complaint. Am J Emerg Med 33: 516-520.

5. Sarko J, Pollack CV Jr (2002) Cardiac troponins. J Emerg Med 23: 57-65.

6. Korff S, Katus HA, Giannitsis E (2006) Differential diagnosis of elevated troponins. Heart 92: 987-993.

7. Hamm C, Bassand JP, Agewall S, Bax J, Boersma E, et al. (2011) ESC Guidelines for the management of acute coronary syndromes in patients presenting without STsegment elevation: The Task Force for the management of acute coronary syndromes (ACS) in patients presenting without persistent ST-segment elevation of the European Society of Cardiology (ESC). Eur Heart J 32: 2999-3054.

8. Agzew Y (2009) Elevated serum cardiac troponin in nonacute coronary syndrome. Clin Cardiol 32: 15-20.

9. Agewall S, Giannitsis E, Jernberg T, Katus H (2011) Troponin elevation in coronary vs. non-coronary disease. Eur Heart J 32: 404-411.

10. Ye J, Chen Z, Wang T, Tong J, Li X, et al. (2010) Role of tissue disorder markers in the evaluation of disease progress and outcome prediction: a prospective cohort study in non-cardiac critically ill patients. J Clin Lab Anal 24: 376-384.

11. Roongsritong C, Warraich I, Bradley C (2004) Common causes of troponin elevations in the absence of acute myocardial infarction-incidence \& clinical significance. Chest 125: 1877-1884.

12. van Bockel EA, Tulleken JE, Ligtenberg JJ, van der Werf TS, Aarts LP, et al. (2005) The significance of elevated troponin levels in the absence of acute cardiac ischaemia. Ned Tijdschr Geneeskd 149: 1879-1883.

13. Esther AP, Bockel V, Tulleken JE, et al. Troponin in septic and critically ill patients. Chest 127: 687-688.

14. Çelebi OO, Diker E, Aydogdu S (2008) Clinical importance of cardiac troponins. Arch Turk Soc Cardiol 36: 269-277.

15. Mehta S, Morales PF, Pillai M (2007) Prognostic implications of elevated troponin in patients with suspected acute coronary syndrome with non-obstructive coronary artery disease. Circulation 116: 624.

16. Amjad A, Ali A, Bashir A, Ali M, Azam MN (2014) Chest pain with raised troponin, ECG changes but normal coronary arteries. BMJ Case Rep 31: 2014.

17. Planer D, Lincoff AM, Moses JW (2011) Prognosis of patients presenting with acute coronary syndromes with elevated serum troponins \& non-obstructive coronary artery disease: The ACUITY trial. JACC 58: 387.

18. Clark M, Payne J (2006) Elevated cardiac troponins: Their significance in acute coronary syndrome and noncardiac conditions. J Okla State Med Assoc 99: 363-367. 
19. Antman EM, Tanasijevic MJ, Thompson B, Schactman M, Mc Cabe CH, et al. (1996) Cardiac-specific troponin I levels to predict the risk of mortality in patients with acute coronary syndromes. N Engl J Med 335: 1342-1349.

20. Heidenreich PA, Alloggiamento T, Melsop K, McDonald $\mathrm{KM}$, Go AS, et al. (2001) The prognostic value of troponin in patients with non-ST elevation acute coronary syndromes: A metaanalysis. J Am Coll Cardiol 38: 478-485.

21. Paul Collinson (2016) High-sensitivity troponin measurements: Challenges and opportunities for the laboratory and the clinician. Ann Clin Biochem 53: 191-195.

22. Goodman DA, Kavsak PA, Stephen A Hill, Worster A (2015) Presenting characteristics of patients undergoing cardiac troponin measurements in the emergency department. CJEM 17: 62-66.

23. Gupta ED, Sakthiswary R (2014) Myocardial infarction false alarm: Initial electrocardiogram and cardiac enzymes. Asian Cardiovasc Thorac Ann 22: 397-401.

24. Jensen JK, Mickley H (2003) Troponin elevation-differential diagnostic considerations and prognostic importance. Ugeskr Laeger 165: 1541-1545.

25. Mannoji H, Hayashi F, Kubota T, Ikeda $Y$, Ishibashi-Ueda $\mathrm{H}$, et al. (2016) Differential Expression of Cardiac Troponin $\mathrm{T}$ and $\mathrm{I}$ in a Patient with Isolated Skeletal Muscular Sarcoidosis. Internal Medicine 55: 3215-3217.

26. Marshall GA, Wijeratne NG, Thomas D (2014) Should general practitioners order troponin tests? Med J Aust 201: 155-157.

27. Nallet O, Gouffran G, Lavie Badie Y (2016) Troponin elevation in the absence of acute coronary syndrome. Ann Cardiol Angeiol (Paris) 65: 340-345.

28. Pandie S, Hellenberg D, Hellig F, Ntsekhe M (2016) Approach to chest pain and acute myocardial infarction. $S$ Afr Med J 106: 239-245.

29. Sandoval Y, Thordsen SE, Smith SW, Schulz KM, Murakami MM, et al. (2014) Cardiac troponin changes to distinguish type 1 and type 2 myocardial infarction and 180day mortality risk. Eur Heart $\mathrm{J}$ Acute Cardiovasc Care 3: 317-325.

30. Sandoval Y, Smith SW, Thordsen SE, Apple FS (2014) Supply/demand type 2 myocardial infarction: Should we be paying more attention? J Am Coll Cardiol 63: 2079-2087.

31. Myint PK, Al-Jawad M, Chacko SM, Chu GS, Vowler SL, et al. (2008) Prevalence, characteristics and outcomes of people aged 65 years and over with an incidental rise in cardiac troponin I. Cardiology 110: 62-67.

32. Normann J, Mueller M, Biener M, Vafaie M, Katus HA, el al. (2012) Effect of Older Age on Diagnostic and Prognostic Performance of High-sensitivity Troponin $T$ in Patients Presenting to an Emergency Department. Am Heart J 164: 698-705.

33. Potter JM, Koerbin G, Abhayaratna WP, Cunningham RD, Telford RD, et al. (2012) Transient troponin elevations in the blood of healthy young children. Clin Chim Acta 413: 702-706.

34. G Stavroulakis, M Papadopoulou, G Koutroulis, V Zouvelou, J Katsavochristos, et al. (2015) Myasthenia gravis. A potential cause of false positively elevated troponin T? Case report and brief review. Int J Cardiol 199: 40-41.

35. Strømme JH, Rolstad OJ, Mangschau A (2000) Troponins and other biochemical cardiac markers-time for a change. Tidsskr Nor Laegeforen 120: 1863-1869.
36. Sugawa S, Sawano K (2015) Clinical Impact of High Sensitive Troponin I Assay. Rinsho Byori 63: 53-61.

37. Tanindi A, Cemri M (2011) Troponin elevation in conditions other than acute coronary syndromes. Vasc Health Risk Manag 7: 597-603.

38. Zhelev Z, Hyde C, Youngman E, Rogers M, Fleming $S$, et al. (2015) Diagnostic accuracy of single baseline measurement of Elecsys Troponin T high-sensitive assay for diagnosis of acute myocardial infarction in emergency department: Systematic review and meta-analysis. BMJ 350: 15 .

39. Devereaux PJ, Chan MT, Alonso-Coello P, Walsh $\mathrm{M}$, Berwanger $\mathrm{O}$, et al. (2012) Association between postoperative troponin levels and 30-day mortality among patients undergoing noncardiac surgery. Vascular Events In Noncardiac Surgery Patients Cohort Evaluation (VISION) Study Investigators. JAMA 307: 2295-2304.

40. Shah AS, Anand A, Sandoval Y, Lee KK, Smith SW, et al. (2015) High-STEACS investigators. High-sensitivity cardiac troponin I at presentation in patients with suspected acute coronary syndrome: A cohort study. Lancet 386: 2481-2488.

41. Kelley WE, Januzzi JL, Christenson RH (2009) Increases of cardiac troponin in conditions other than acute coronary syndrome and heart failure. Clin Chem 55: 2098-2112.

42. Maeder M, Fehr T, Rickli H, Ammann P (2006) Sepsisassociated myocardial dysfunction: Diagnostic and prognostic impact of cardiac troponins and natriuretic peptides. Chest 129: 1349-1366.

43. Spies C, Haude V, Fitzner R, Schröder K, Overbeck M, et al. (1998) Serum cardiac troponin T as a prognostic marker in early sepsis. Chest 113: 1055-1063.

44. Goodkin DA, Young EW, Kurokawa K, Prütz KG, Levin NW (2004) Mortality among hemodialysis patients in Europe, Japan, and the United States: Case-mix effects. Am J Kidney Dis 44: 16-21.

45. Schiffrin EL, Lipman ML, Mann JF (2007) Chronic kidney disease: Effects on the cardiovascular system. Circulation 116: 85-97.

46. Khan NA, Hemmelgarn BR, Tonelli M, Thompson CR, Levin A (2005) Prognostic value of troponin T and I among asymptomatic patients with end-stage renal disease: $A$ meta-analysis. Circulation 112: 3088-3096.

47. Aviles RJ, Askari AT, Lindahl B, Wallentin L, Jia G, et al. (2002) Troponin $T$ levels in patients with acute coronary syndromes with or without renal dysfunction. N Engl J Med 346: 2047-2052.

48. Francis GS, Tang WH (2004) Cardiac troponins in renal insufficiency and other non-ischemic cardiac conditions. Prog Cardiovasc Dis 47: 196-206.

49. Baillard C, Boussarsar M, Fosse JP, Girou E, Le Toumelin $P$, et al. (2003) Cardiac troponin I in patients with severe exacerbation of COPD. Intensive Care Med 29: 584-589.

50. Martins CS, Rodrigues MJ, Miranda VP, Nunes JP (2009) Prognostic value of cardiac troponin I in patients with COPD acute exacerbation. Neth J Med 67: 341-349.

51. Fruchter O, Yigla M (2009) Cardiac troponin-I predicts longterm mortality in chronic obstructive pulmonary disease. COPD 6: 155-161.

52. Mehta NJ, Jani K, Khan IA (2003) Clinical usefulness and prognostic value of elevated cardiac troponin I levels in acute pulmonary embolism. Am Heart J 145: 821-825. 
53. Yalamanchili K, Sukhija R, Aronow WS, Sinha N, Fleisher AG, et al. (2004) Prevalance of increased cardiac troponin I levels in patients with or without acute pulmonary embolism and relation of increased cardiac troponin I levels with in-hospital mortality in patients with acute pulmonary embolism. Am J Cardiol 93: 263-264.

54. Moores L, Aujesky D, Jiménez D, Díaz G, Gómez V, et al. (2010) Pulmonary Embolism Severity Index and troponin testing for the selection of low-risk patients with acute symptomatic pulmonary embolism. J Thromb Haemost 8: 517-522.

55. Gunnewiek JM, Van Der Hoeven JG (2004) Cardiac troponin elevations among critically ill patients. Curr Opin Crit Care 10: 342-346.

56. Chew DP, Briffa TG, Alhammad NJ, Horsfall M, Zhou J, et al. (2015) High sensitivity-troponin elevation secondary to non-coronary diagnoses and death and recurrent myocardial infarction: An examination against criteria of causality. Eur Heart J Acute Cardiovasc Care 4: 419-428.

57. Potter JM, Simpson AJ, Kerrigan J, Southcott E, Salib MM, et al. (2017) Cross-sectional study of high-sensitivity cardiac troponins $\mathrm{T}$ and $\mathrm{I}$ in a hospital and community outpatient setting. Clin Biochem 50: 105-109.

58. Jensen JK, Ueland T, Aukrust $P$, Antonsen L, Kristensen SR, et al. (2012) Highly sensitive troponin T in patients with acute ischemic stroke. Eur Neurol 68: 287-293.

59. Huhtakangas J, Lehto H, Seppä K, Kivisaari R, Niemelä M, et al. (2015) Long- term excess mortality after aneurysmal subarachnoid hemorrhage: patients with multiple aneurysms at risk. Stroke 46: 1813-1818.

60. Nieuwkamp DJ, de Wilde A, Wermer MJ, Algra A, Rinkel GJ (2014) Long-term outcome after aneurysmal subarachnoid hemorrhage-risks of vascular events, death from cancer and all-cause death. J Neurol 261: 309-315.

61. Devereaux PJ, Biccard BM, Sigamani A, Xavier D, Chan MTV, et al. (2017) Association of Postoperative HighSensitivity Troponin Levels With Myocardial Injury and 30-Day Mortality Among Patients Undergoing Noncardiac Surgery. Writing Committee for the VISION Study Investigators. JAMA 317: 1642-1651

62. de Lemos JA, Drazner MH, Omland T, Ayers CR, Khera A, et al. (2010) Association of troponin T detected with a highly sensitive assay and cardiac structure and mortality risk in the general population. JAMA 304: 2503-2512.

63. Bakshi TK, Choo MK, Edwards CC, Scott AG, Hart HH, et al. (2002) Causes of elevated troponin I with a normal coronary angiogram. Intern Med J 32: 520-525.

64. Newby LK, Jesse RL, Babb JD, Christenson RH, De Fer TM, et al. (2012) ACCF 2012 Expert Consensus Document on Practical Clinical Considerations in the Interpretation of Troponin Elevations. J Am Coll Cardiol 60: 2427-2463. 